\title{
Participatory resource monitoring as a means for promoting social change in Yunnan, China
}

\author{
JEANNETTE VAN RIJSOORT ${ }^{1, *}$ and ZHANG JINFENG ${ }^{2}$ \\ ${ }^{1}$ Department of Environmental Sciences, Forest and Nature Conservation Policy Group, Wageningen \\ University, P.O. Box 342, 6700 AH Wageningen, The Netherlands; ${ }^{2}$ Research Institute of Economic \\ Forests, Yunnan Academy of Forestry, Heilongtan, 650204 Kunming, P.R. China; *Author for cor- \\ respondence (e-mail: jvanrijsoort@casema.nl; fax: +31-317-478078)
}

Received 20 March 2004; accepted in revised form 1 October 2004

Key words: China, Locally-based monitoring, Participatory monitoring, Perceptions, Process approach, Social change, Yunnan

\begin{abstract}
Recent international forest policies stimulate involvement of communities in forest management as a strategy to improve biodiversity conservation and the quality of local livelihoods. Increasingly, the role of local people in monitoring forest resources is also acknowledged. This paper presents a participatory resources monitoring (PRM) system developed and implemented by representatives of 12 villages, six each within and adjacent to two nature reserves in Yunnan, China. The short-term objectives are to monitor resource and wildlife abundance, resource use, wildlife damage to crops, and land use. Main methods used by the village monitoring team are: (1) observation through forest walk, (2) village interview, and (3) market survey. Monitoring is implemented throughout the year to fit in the daily work of villagers. Staff from the nature reserve or forestry bureau provide support by visiting the villages several days per year. Results indicate that participatory monitoring is a valuable tool for villagers to engage in self-owned management actions. We discuss how monitoring is also a process which could lead to social change. Based on narratives we suggest that participatory monitoring builds trust between stakeholders, changes perceptions and attitudes and leads to more democratic and transparent decision-making. In discussing accuracy, we argue that all stakeholders perceive and interpret nature differently based on different worldviews, knowledge systems, values and beliefs. We argue that if participatory monitoring is to be sustainable, community-based monitoring - preferably linked to scientific monitoring and patrolling - should be designed as a discursive institution where the process of building social capital and inter-actor learning is extremely important. Finally, we briefly reflect upon efforts to scale up participatory monitoring.
\end{abstract}

\section{Introduction}

For more than two decades international conservation policies have stimulated the involvement of local communities in forest management as a strategy to improve natural resource conservation and the quality of local people's life (e.g. Convention on Biological Diversity, Intergovernmental Panel on Forests/ Intergovernmental Forum on Forests/United Nations Forum on Forests). The assumption behind these policies is that if people are involved in managing the resources they depend on, it could lead to increased developmental benefits and a higher motivation to conserve and sustainably use the resources (Fisher 1995; 
Kellert et al. 2000). China was the first country in mainland Southeast Asia that devolved responsibilities for administration and legislation to the local level (Dupar and Badenoch 2002). Starting in the late 1970s agricultural land ownership was decentralised, followed by decentralisation of forestlands in the early 1980s. Use rights were granted to households ('household forests') and to villages ('collective forests') for a period of 30 years. In 1998, Village Committees and village leaders were democratically elected, and received responsibilities to manage natural resources by law (Xu et al. 2001). Township government and the Village Committee can develop their own regulations for natural resources management of 'their' lands and forests, as long as they comply with the Chinese constitution and laws, and with county regulations and policies (Dupar and Badenoch 2002).

However, China's series of decentralising reforms have focussed on allocating rights and responsibilities to lower levels without simultaneously strengthening the co-ordinating and supporting structures for sound environmental governance at village and township levels (Dupar and Badenoch 2002). Monitoring is a central component of such good environmental governance as it ensures that threats are identified and addressed (Sheil 2001). Current practices for monitoring natural resources in China are scientific monitoring by research institutes and patrolling by forestry and nature reserve staff. Only recently it has been internationally acknowledged that there is scope for decentralising monitoring as well. Lawrence and van Rijsoort (2003) indicate that the involvement of local people in monitoring can be very valuable for various reasons. Local people have a store of knowledge about forests and resource use. Local involvement in monitoring also enhances villagers' awareness and capacity for sustainable resource use and enhances the transparency of management decision-making. Furthermore, it improves relations between villagers and management staff, and it is more sustainable as it uses locally available capacity and resources. Villagers themselves want to be involved because they see declines in some resources on which they depend for their livelihoods. They wish to be able to continue resource use in the future, based on realistic and location-specific regulations. Information from monitoring can also be used by communities to warrant (or expand) community use rights.

In and around the nature reserves in Yunnan, China, the livelihoods of local people highly depend upon the reserves. Because of this high dependence, various nature reserve management plans identified a need for participatory resources monitoring (PRM) in the collective forests in and around the nature reserve. Moreover, the Yunnan Nature Reserve Rules and Regulations allow sustainable resource use by local people in specified parts of the nature reserve. The Yunnan Forestry Law stipulates that a joint management system by park administration and local people should be established for the nature reserve and community forests. For this reason an experimental scheme has been established by the authors within and adjacent to two nature reserves in Yunnan, China. 
This paper presents local perceptions on environmental change and management decisions that need to be taken. The methodology of Participatory Resources Monitoring will be briefly introduced; for more information on the methodology development and its values for forest conservation and local needs we refer to van Rijsoort and Zhang (2002) and Rijsoort and Zhang (in press). The PRM was established based on the notion that it can be both a product and a process. On one hand it provides insight in the status and use of natural resources as a basis for better informed decision-making, and on the other hand it improves communication between stakeholder, builds capacity and enhances transparent decision-making (Lawrence and Elphick 2002). Based on narratives we discuss how the process of participatory monitoring may lead to social change. We will furthermore discuss the accuracy and sustainability of participatory monitoring and touch upon possibilities for scaling it up more widely within China.

\section{Main features of participatory resources monitoring methodology}

\section{Study area}

Participatory resources monitoring is being implemented in and around Xiaoheishan Nature Reserve and Tongbiguan Nature Reserve in Yunnan Province of the P.R. China (Figure 1). A 3-km broad strip of land adjacent to each nature reserve is considered a 'bufferzone'. The main characteristics of these nature reserves in respect to management and local livelihoods are summarised in Table 1.
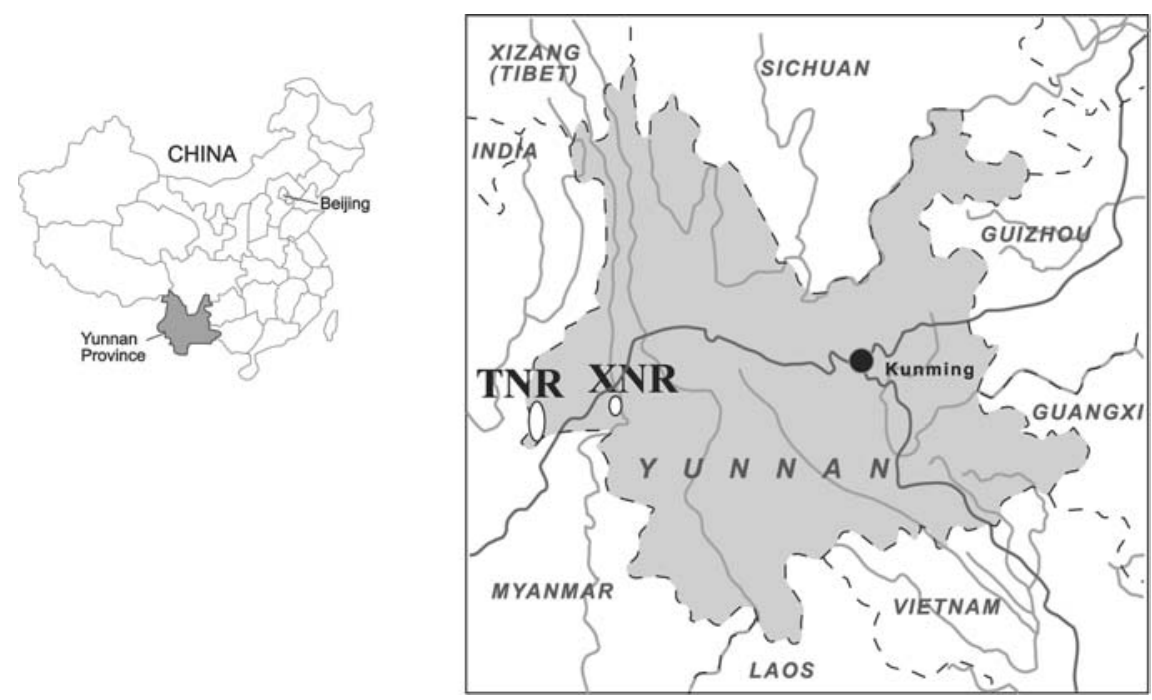

Figure 1. Location of Xiaoheishan (XNR) and Tongbiguan nature reserves (TNR) in Yunnan, China. 


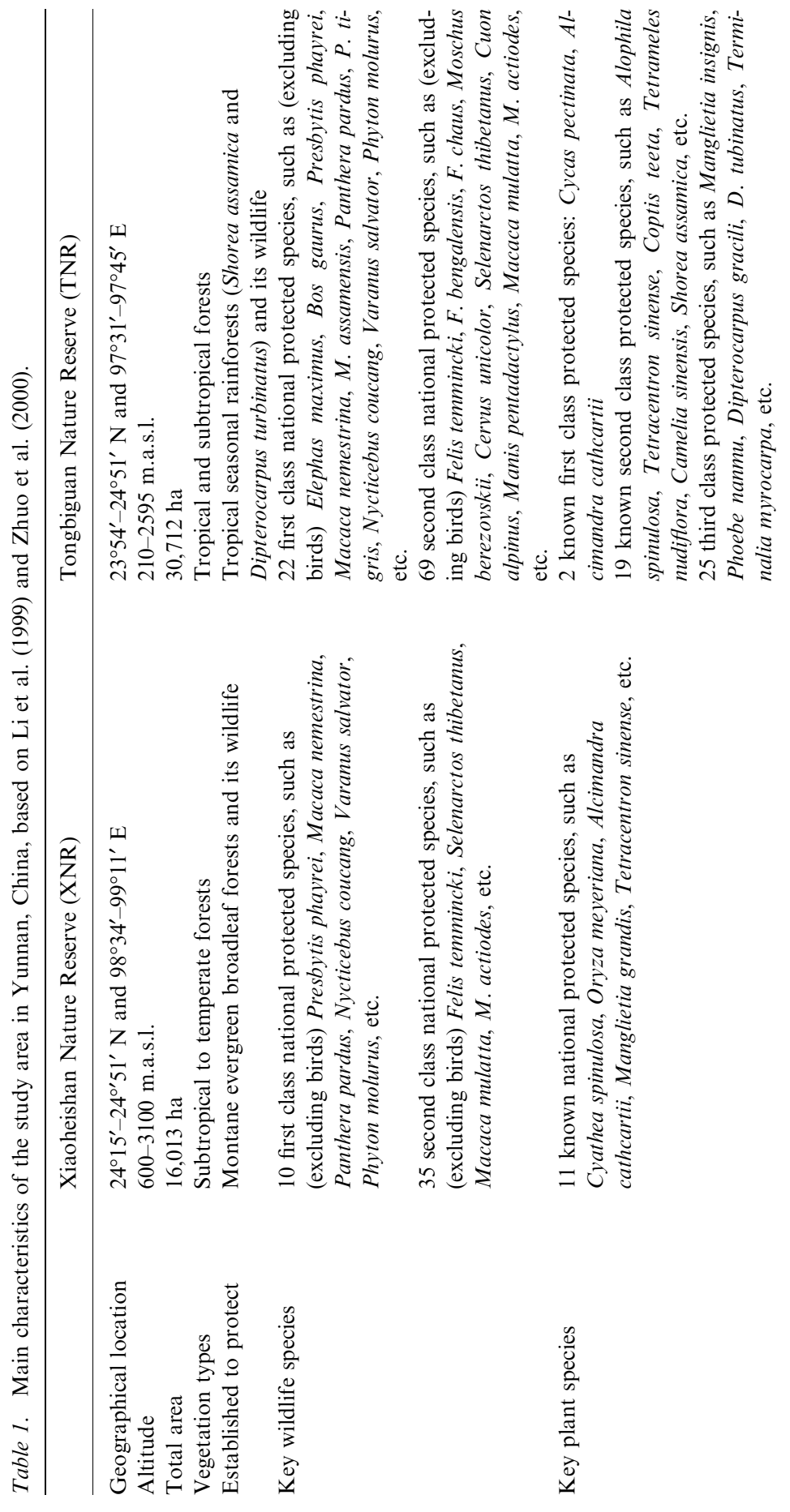



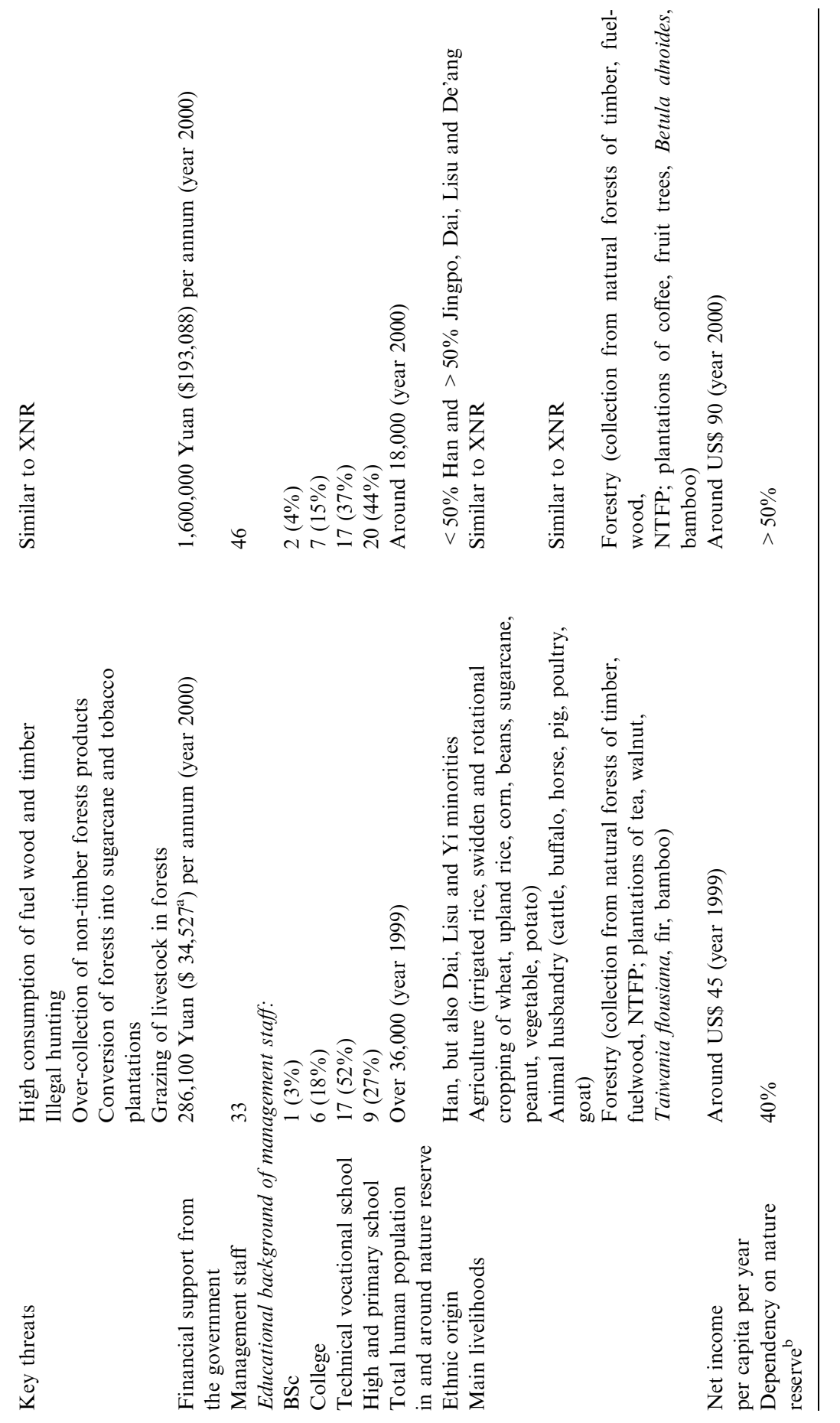


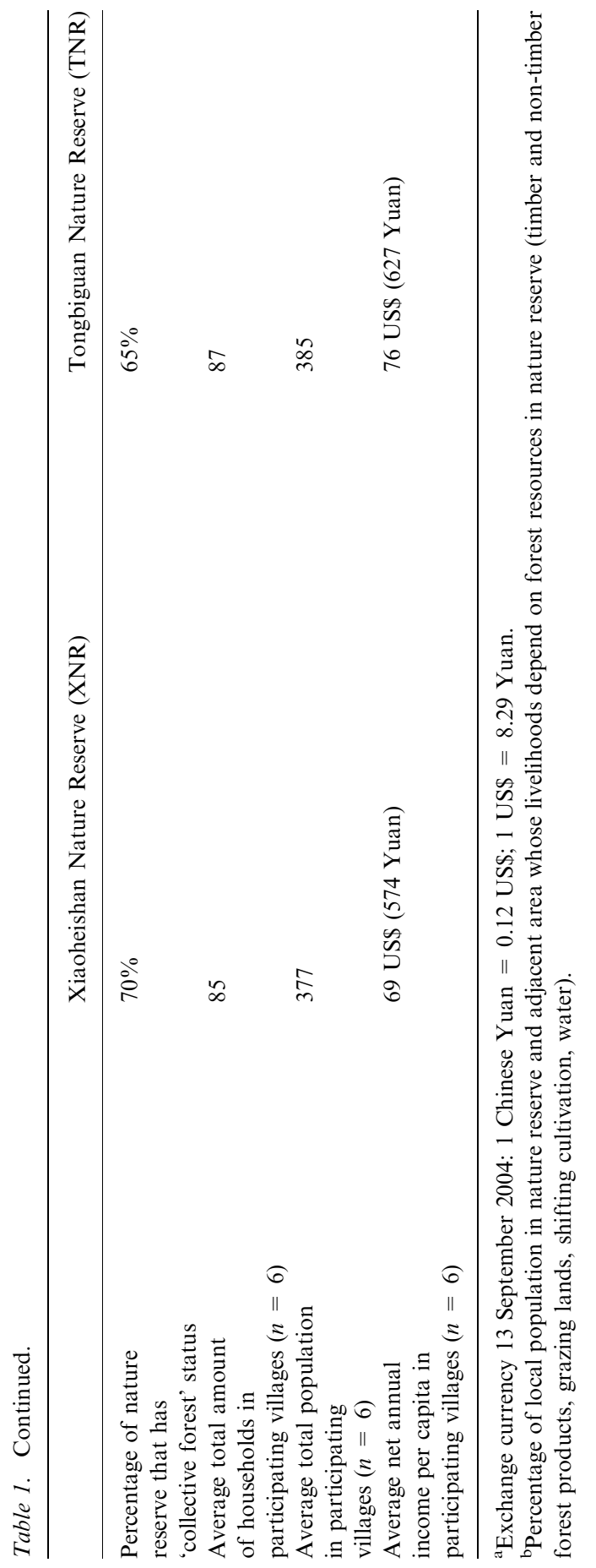


Participatory resource monitoring was established in July 2001. In each of the nature reserve, 6 villages participated, selected using four criteria:

- People are highly dependent on forests in and around the nature reserve for the livelihoods.

- There is a conflict in resource use, or resource use is believed to be unsustainable.

- Villages are located in an ecologically sensitive area.

- Villages represent the geographic condition of the nature reserve area.

These factors were chosen based on the idea that participatory monitoring of forest resources is only meaningful in areas where forests are directly linked to people's livelihoods and where resources are under dynamic pressure, causing a need for urgent management actions. Representation of the geographic condition of the area was chosen as another criteria to enable wider application if the method was found successful.

\section{Monitoring team}

In each of the villages a PRM team was established, using the criteria below. Ideally, the members of this team should represent the heterogeneity of the village. However, as the method was new and villagers did not yet fully comprehend the consequences, we instead chose criteria based on the villagers' leaders' idea of representation:

- The village leader or one of the leaders, who has the support of the villagers and can mobilise and motivate them.

- Someone who is known and respected to have substantial knowledge of the forests and its wildlife, such as the village forest guard. A village forest guard is a villager (usually a former hunter or old man with substantial knowledge of the forests and its wildlife) who receives a small fee from the Nature Reserve Management Station to patrol the collective forests and nature reserve for illegal cases and wildlife abundance.

- A womens representative.

- Either another knowledgeable villager or someone who can read and write Han Chinese in case the other team members cannot.

A staff member of the nature reserve management station or office was added to the monitoring team to improve co-operation and communication. The monitoring team is responsible for collecting, recording and analysing data, involving other villagers in the process.

The methodology for PRM has been developed with direct involvement of this monitoring team and additional management staff. Through a facilitated workshop in each of the two nature reserve, they identified objectives, indicators, methodologies, data analysis and dissemination. Participants in both workshops where (1) the monitoring teams from the six villages, (2) local 
nature reserve and forestry staff, and (3) project officials from the county, prefecture and provincial forestry department. In September 2002, we evaluated the method through a similar workshop with same participants, and on the basis of adjusted needs we slightly modified the targets and simplified the indicators.

\section{Benefits and obstacles}

In the facilitated workshop to develop the methodology, the villagers and staff were asked to indicate the benefits and obstacles they thought they would meet, if they would be involved in the resource monitoring. These are listed in Table 2. Some benefits and problems were perceived to be the same among villagers and staff, but there were also differences. Staff thought that through being involved in monitoring, villagers would better understand the benefits from certain species. The villagers indicated that they are very aware of this, instead they feared that monitoring would lead to further restrictions in their resource use. The staff thought that villagers require a training, e.g. in species recognition, before they can do the monitoring. The villagers on the contrary indicated that they know the species already, although they name them with local names instead of scientific names. They expressed their idea that if they need training, it would be in how to sustainably use resources and what would be the benefits of sustainable use on the long run.

\section{Monitoring objectives}

The objectives identified by the villagers and government staff are listed below. Monitoring targets are separately listed in Appendix 1.

Short-term objectives:

1. To monitor the abundance of target species and change in target land uses

2. To monitor resource use by villagers

3. To analyse problems in resource abundance and use, and suggest management actions

4. To monitor and analyse wildlife damage to crops and livestock and suggest possible solutions

5. To develop and improve monitoring indicators and methods and adjust monitoring targets if necessary

Long-term objectives:

1. To improve conservation and sustainable resource use in collective forests and nature reserve

2. To improve the local economy through sustainable resource use

3. To improve knowledge among villagers and staff on resources abundance, distribution, value and use 


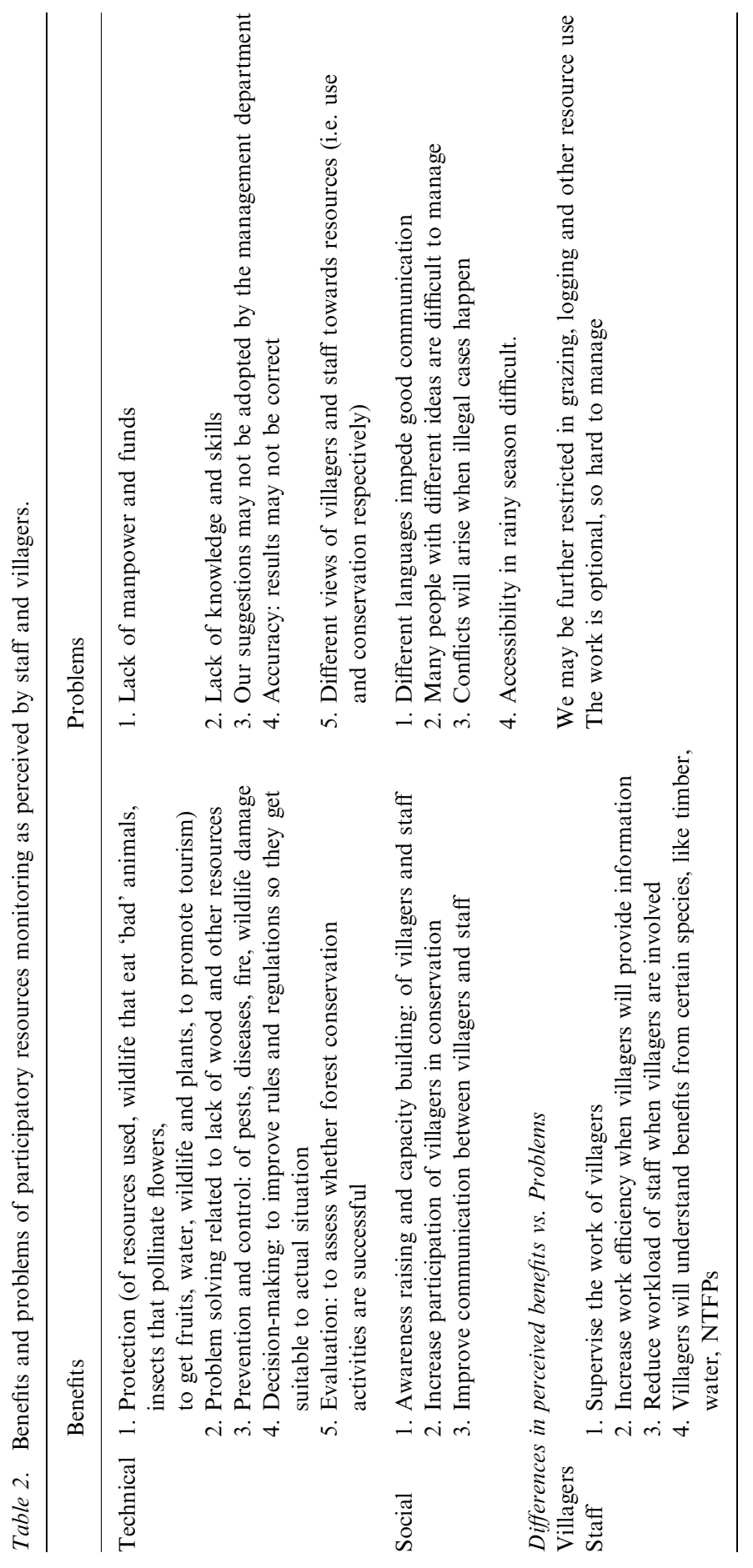


4. To improve capacity of villagers and staff to plan and conduct monitoring and to analyse reasons of change

5. To improve relationship between villagers and staff, and among villagers

\section{Indicators and field methods}

The monitoring targets selected by villagers and staff are natural resources, wildlife, wildlife damage, and land use (Appendix 1). Natural resources are here defined as resources consumed by the villagers, being timber, fuel wood and Non-Timber Forest Products (NTFPs) including fish, frog, small birds etc. Wildlife is defined as all fauna species which are not consumed (anymore) and/ or which are protected by Yunnan law. Resource and wildlife abundance was monitored qualitatively. It is too difficult and time consuming to monitor abundance quantitatively. Moreover, the philosophy behind PRM is that an idea of trends in abundance is sufficient to define management actions for resources under threat. Resource use and wildlife damage was monitored quantitatively, as the villagers' concept of use and damage is quantitative (e.g. ' 8 chicken were eaten by wild cats', 'each household consumes 3 pai of fuelwood each year'). Land use was monitored both quantitatively and qualitatively (e.g. ' $100 \mathrm{mu}$ of forest planted', 'pine forest is ill'). See Table 3 for indicators and methods.

\section{Analysis of findings and adaptation of management}

Villagers and staff analysed the monitoring findings after 1 year during a village meeting. They collaboratively suggested management-decisions to address perceived problems. These have been presented to the management office, who in their turn presented to the project and the Yunnan Provincial Forestry Bureau. Results are presented in Table 4.

\section{Costs}

Because PRM is a new activity and villagers are poor and busy with farming, the project initially provided a budget of around US\$ 1000 to each monitoring team for the first year of implementation. This budget contained allowance for villagers and staff, and support for transportation, village meetings, stationery, etc. In general, villagers' extra time input is 9-14 days, and staff input is around 5 days per year. Ruili Management Office of Tongbiguan provided simple cameras for free to some villages. It was anticipated that with the success of the monitoring method after a few years, the villagers would be motivated to continue. However, after the first year, the project provided no budget. As villagers remain poor and busy, the Ruili Management Office provided US $\$ 60$ 


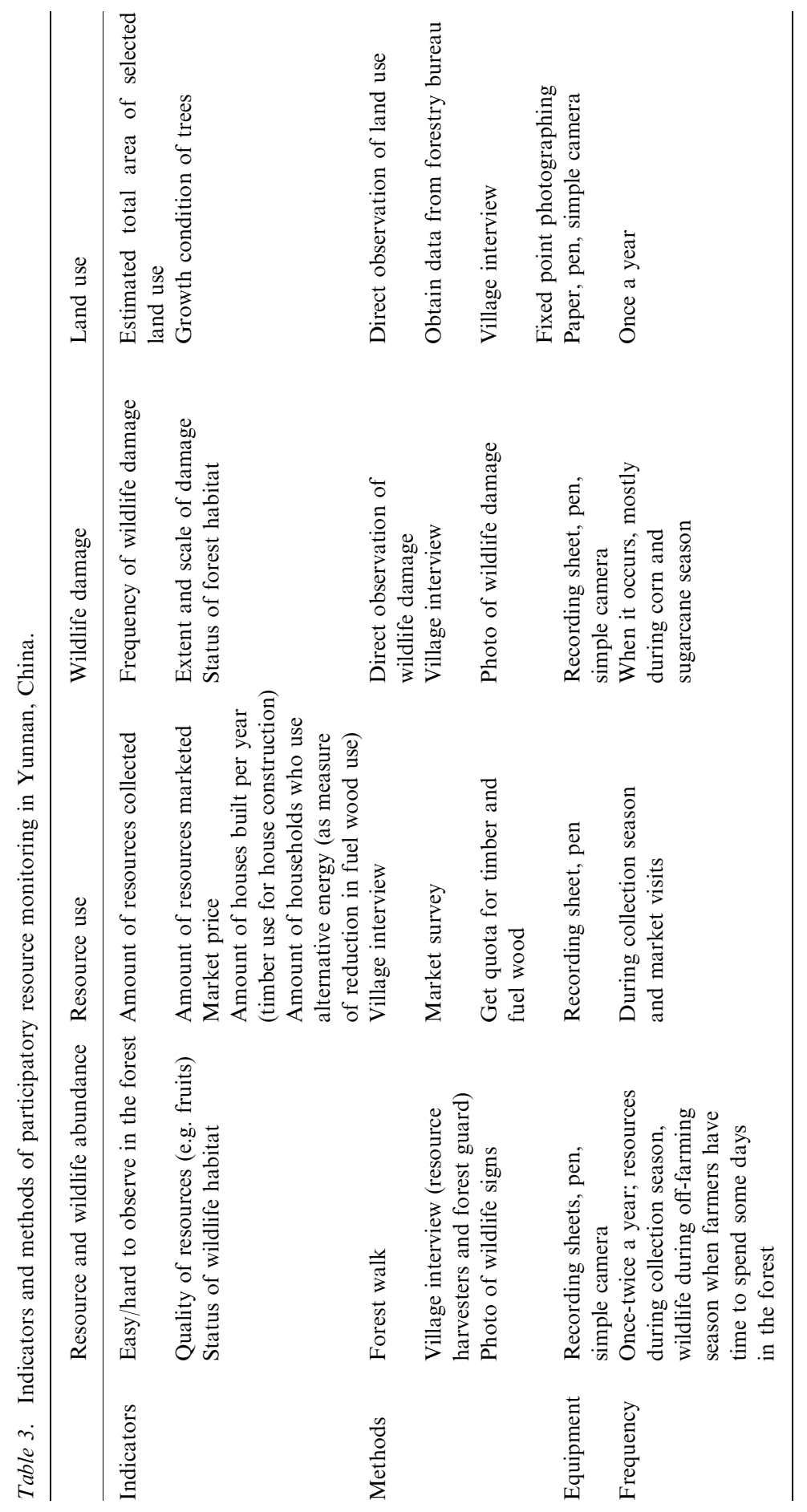




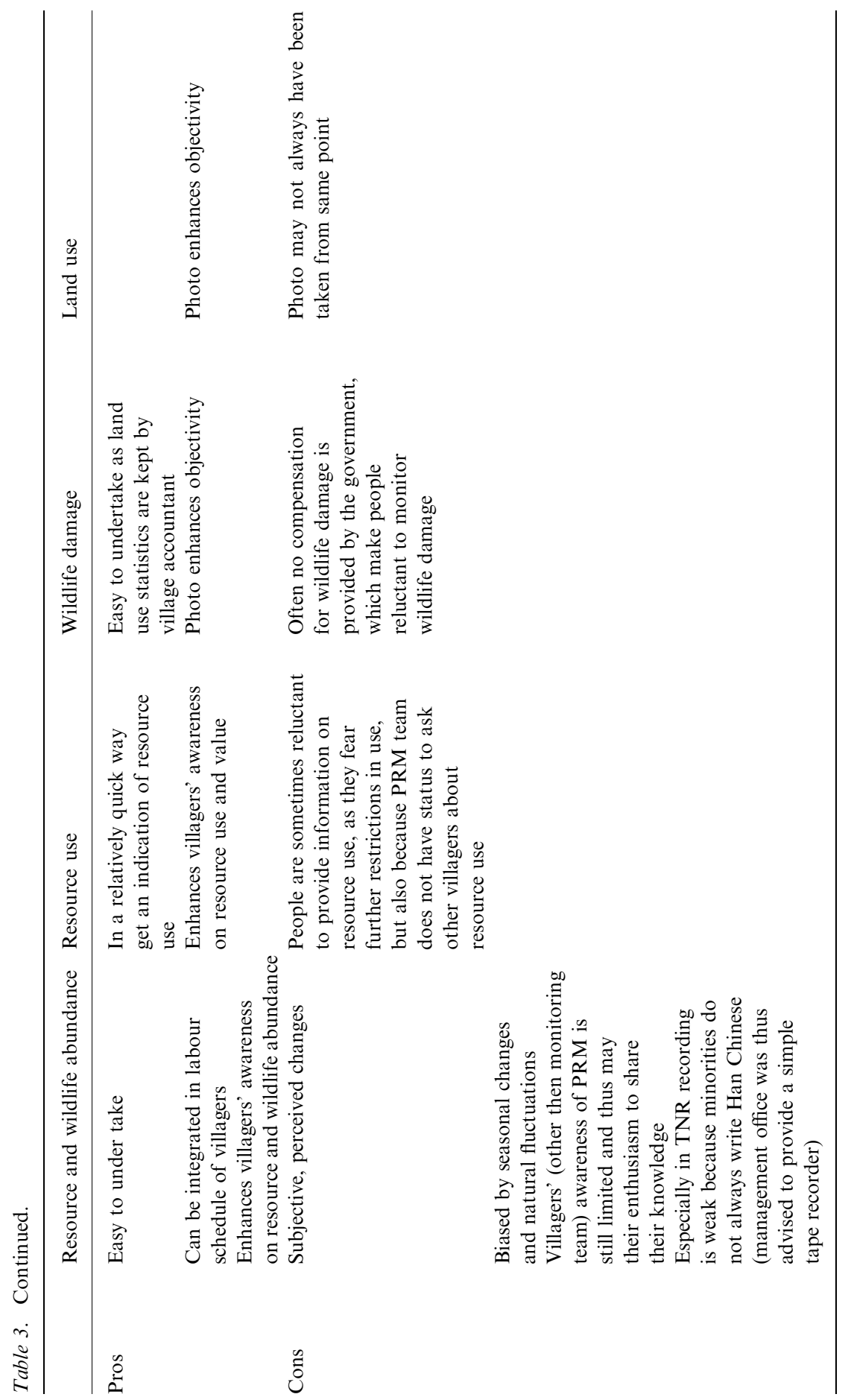


to each village, as well as free seedlings of Dendrobium nobile (a medicinal orchid) to establish a nursery. It is yet to be seen whether this small investment in starting PRM will provide a sustainable basis for the continuation of the monitoring.

\section{Results: perceptions of environmental change and management actions taken}

Table 4 summarises the main technical results of PRM outlined in terms of perceptions of villagers and the actions they have taken to address these perceptions. The time period of monitoring is too short to determine whether actual abundance is changing in the way it is perceived. Villagers in both nature reserves perceived a reduction in abundance of most species of medicinal plants, wild fruits, timber and fuel wood, fish and frogs. Villagers attribute this decline to unsustainable collection and destruction of habitats. In Tongbiguan $75 \%$ of the villages suggest that there are less wild fruits because the wildlife dispersing these fruits had become rare. In this nature reserve the establishment of sugarcane plantations is seen as a threat to several resources, such as medicinal plants ( $83 \%$ of the respondents), fuelwood $(40 \%)$, timber $(40 \%)$. All respondents think the rarity of fruits is causing more wildlife damage to crops. Half of the respondents in both nature reserves attributed the perceived decline in fish and frogs to the villagers' use of pesticides in agriculture.

Still abundant resources were believed to be wild vegetables, fungi, bamboo and birds. This abundance is because villagers plant wild vegetables and bamboo in homegardens and are too busy to collect fungi which is very time consuming. Fungi habitats are believed to be abundant ( $80 \%$ of respondents in Xiaoheishan). In Tongbiguan $67 \%$ of respondents believe that the high abundance of wild vegetables is also due to the fact that these species have a high adaptability. Bird populations are believed to have increased as firearms have been confiscated.

There were also different perceptions between the two nature reserves. All villages in Xiaoheishan perceived a general increase in wildlife abundance, though mainly of smaller wildlife. In Tongbiguan most large wildlife was difficult to see which may have been translated into a perception of decline in wildlife abundance. All villagers in Xiaoheishan believe the increase in populations of small wildlife and insufficient food resources for wildlife in the natural habitat lead to an increase in cases of wildlife damage to crops. In Tongbiguan all villagers believe the increased establishment of sugarcane plantations causes more wildlife to come to their fields.

On the basis of perceived change and its reasons, villagers suggested several management-decisions and took some concrete management actions. Several villagers adapted or drafted village regulations to address the perceived problems. In Tongbiguan, $83 \%$ of the respondents suggested to regulate purchases by herb dealers. The collection of medicinal orchids in both nature 


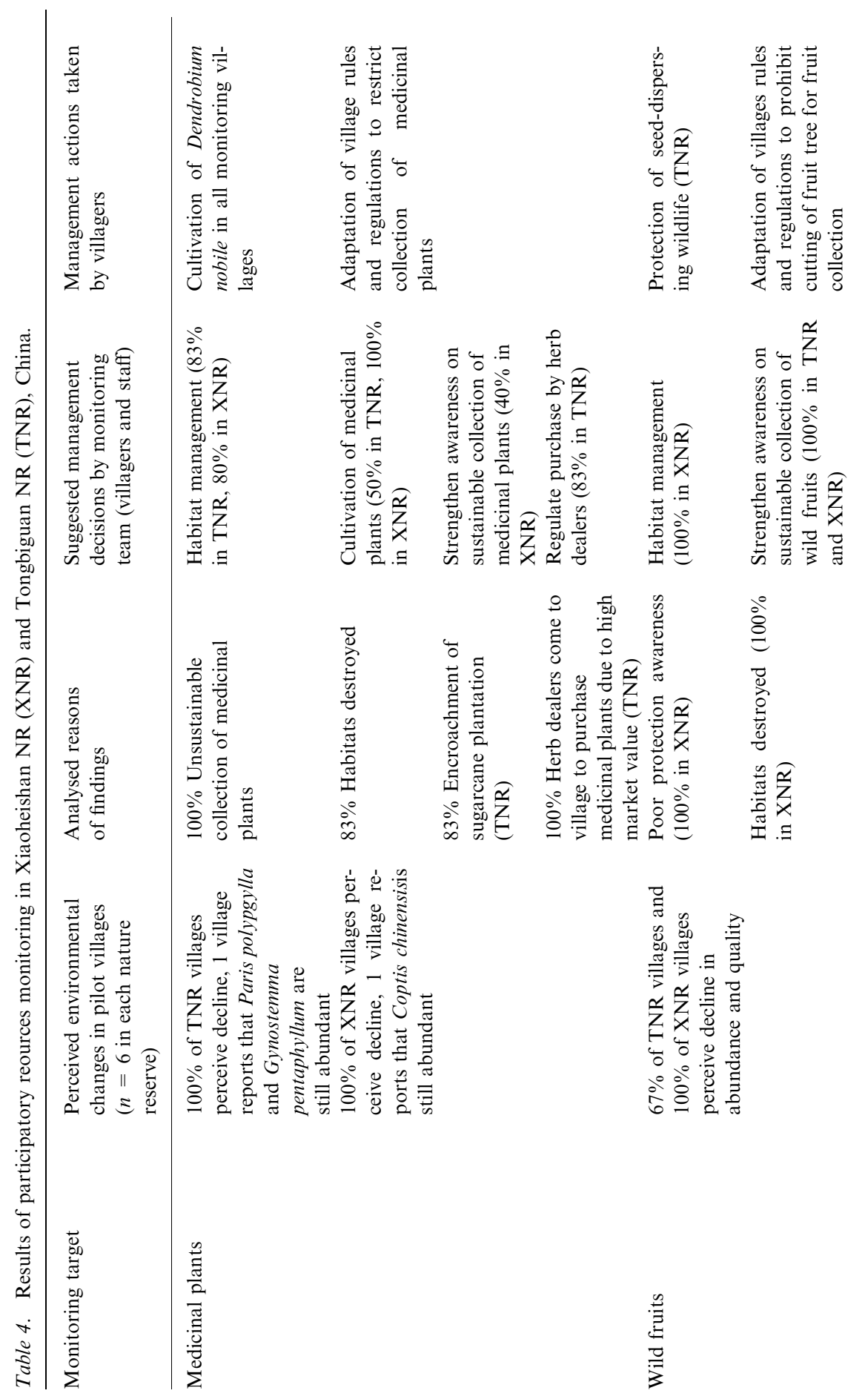



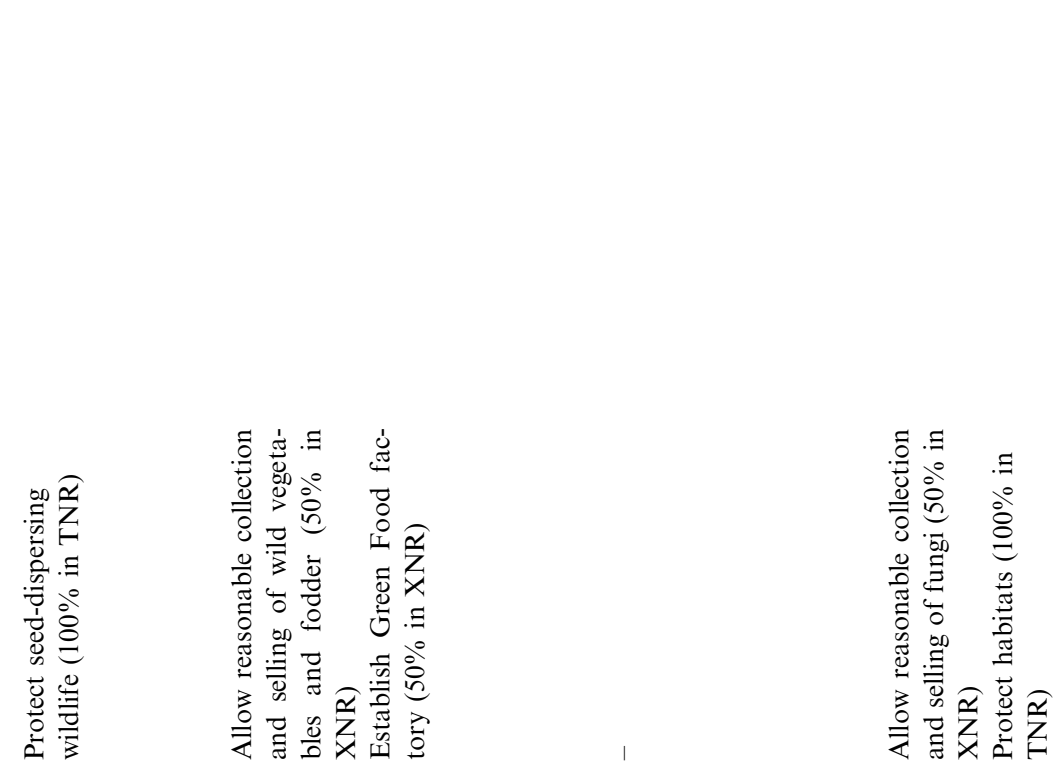

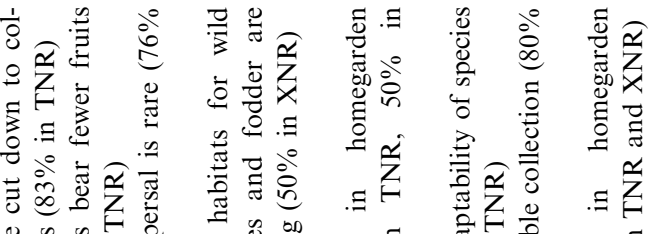

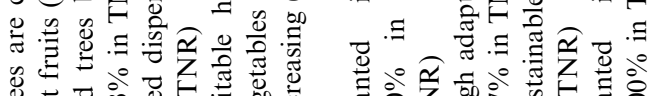

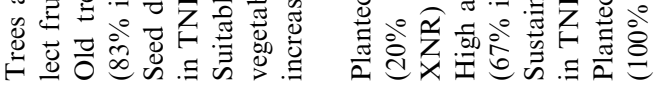

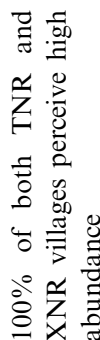

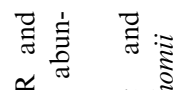

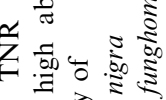

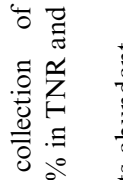

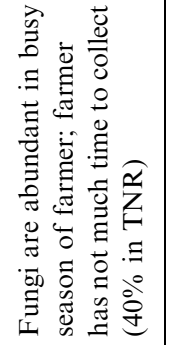

要

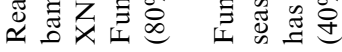

焉

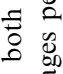

拧 零

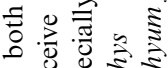

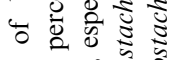

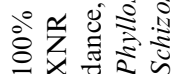

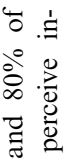

学总

我

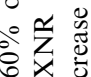

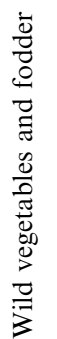

可

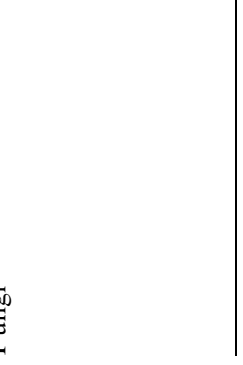




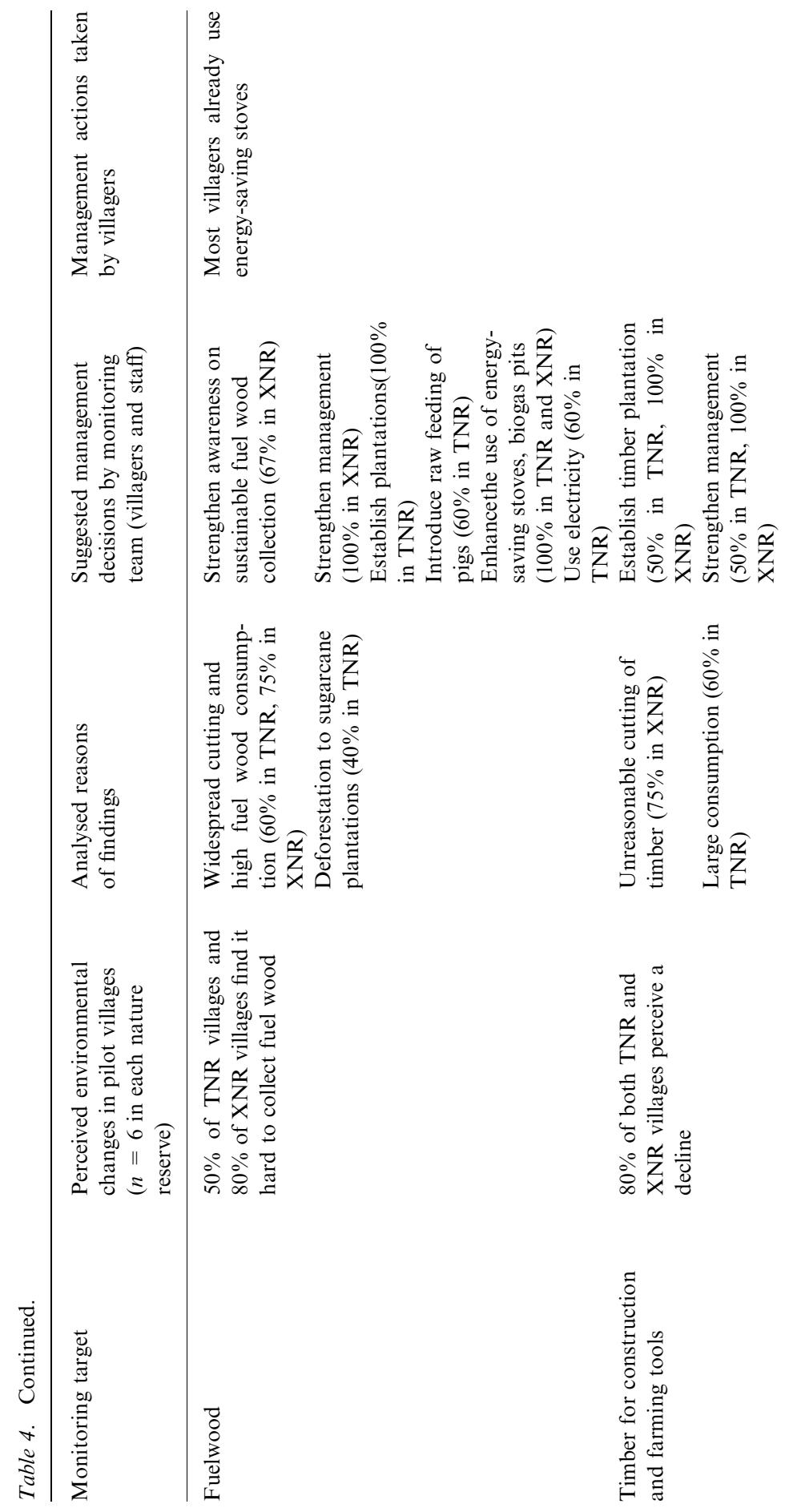




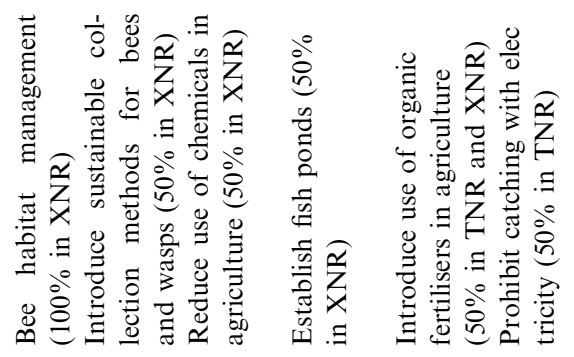

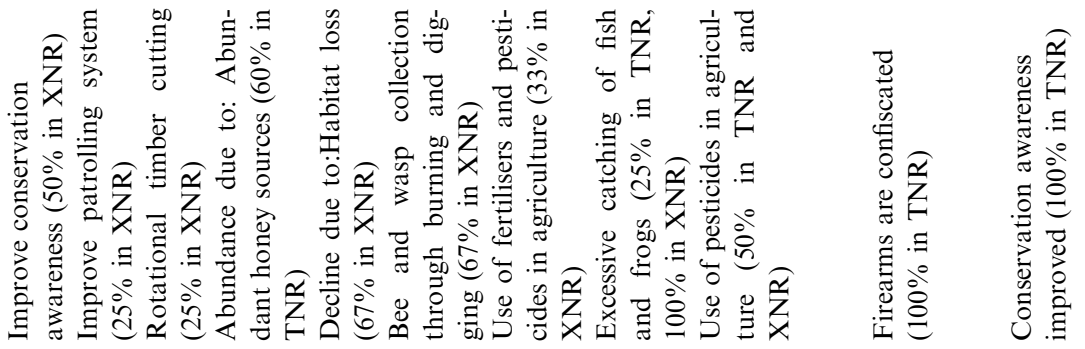
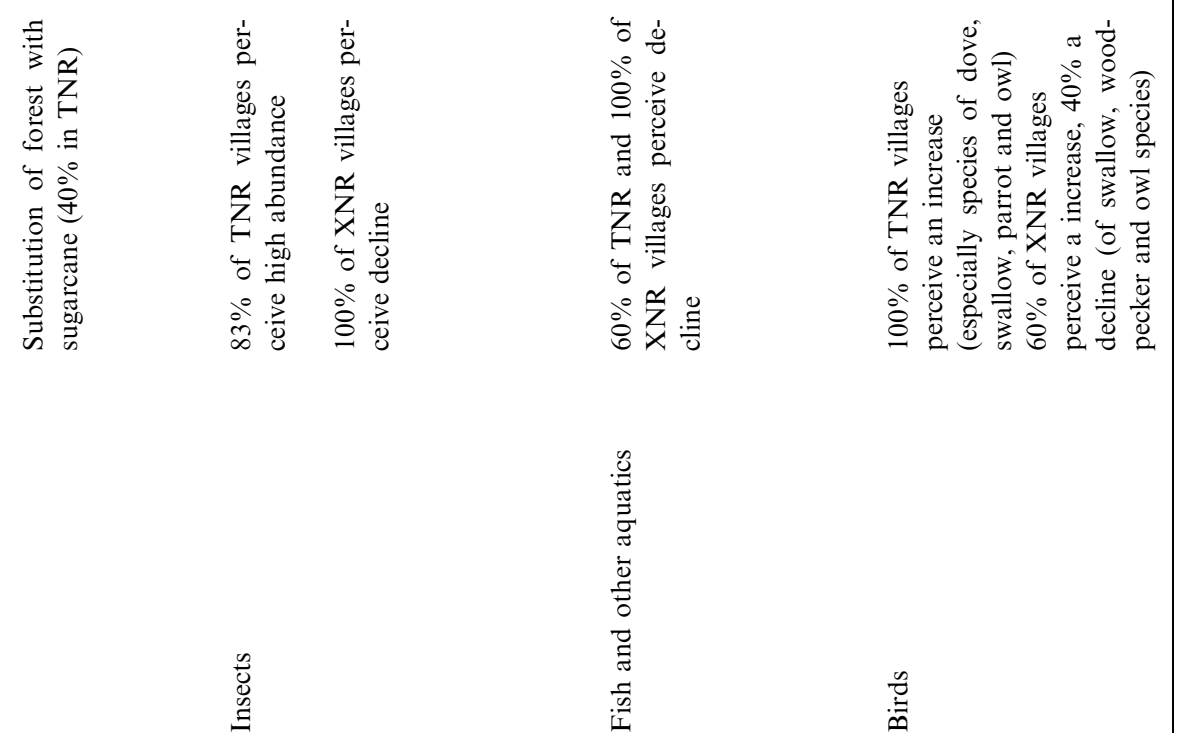


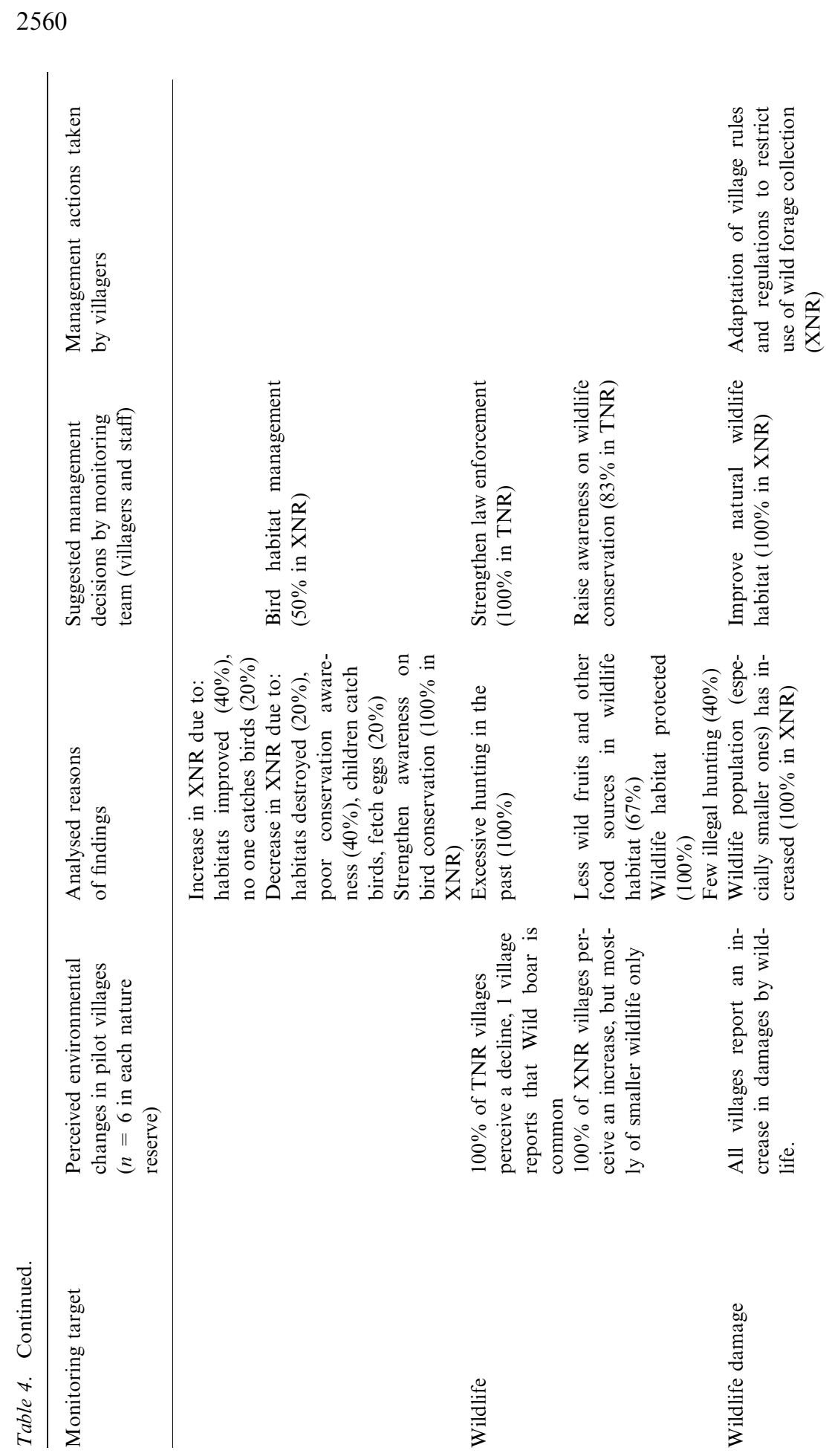




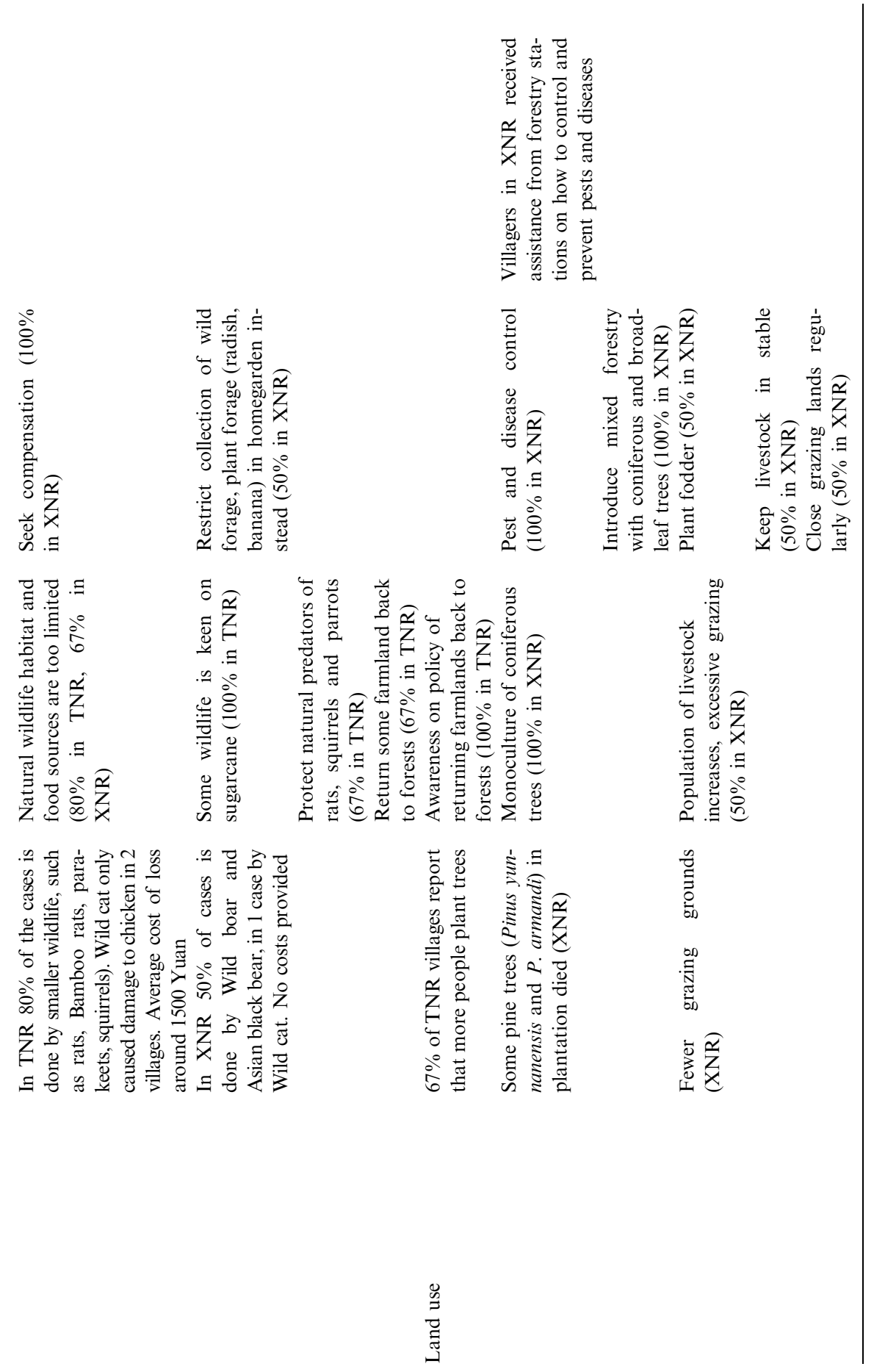


reserves has been restricted due to the monitoring, and all villages started to cultivate the medicinal orchid Dendrobium nobile. Village regulations were also adapted to prohibit tree cutting for fruit collection. All villagers in Tonbiguan suggested the need to protect seed-dispersing wildlife. To address the problem of wildlife damage, $50 \%$ of the respondents in Xiaoheishan restricted the collection of wild forage for their livestock so as to secure natural food sources for wildlife such as Wild boar, Barking deer and Asian black bear (see Appendix 1 for latin names). Plantations of radish and banana in homegardens were proposed as an alternative. For those suggested management decisions that need external (financial) support or approval, no concrete actions have yet been taken (except for the Dendrobium nobile homegarden). All villages in both nature reserves suggested using more energy-saving stoves to limit fuel wood use, which is already advocated by the Yunnan government. Half of the respondents in Xiaoheishan suggested the establishment of fish ponds, and half of the respondents in Tongbiguan suggested prohibiting electrical fishing methods. Finally, in both nature reserves half of the respondents suggested to use organic fertilisers on their fields.

For those resources for which an increase or high abundance was perceived, such as fungi and wild vegetables, half of the respondents suggested allowing sustainable collection from the wild, and establishing a Green Food Factory. This is a village- or township-based factory processing wild vegetables, collected from natural forests, to be sold to urban markets. The Green Food market is emerging in Yunnan as more urban people wish to consume 'natural products' to which no pesticides have been applied.

Some of the proposed management decisions are still rather general, such as 'allow reasonable collection', possibly due to limited knowledge on sustainable use of NTFPs. Some villages in Xiaoheishan (25\%) suggested rotational cutting for timber species, indicating more experience in managing this resource.

It is too early to quantitatively assess the impact of changed village rules and regulations and Dendrobium nobile domestication on the reduction of threats to forests and biodiversity. Furthermore, changes perceived by villagers may be confounded by natural fluctuations. In these cases, information from conventional scientific monitoring and patrolling could be used to cross check villagers' perceptions.

\section{Discussion}

\section{Variability of resource use data}

The data on resource use are not presented in the paper as they were not systematically recorded by the villagers. Villages that did record their usage of resources, did so in different units which made it impossible to compare among villages and analyse. A lesson is that more attention should be paid to standardise resource use monitoring. 


\section{Ownership of management decisions}

Some management actions have been taken at village level, such as changing village rules and regulations to restrict collection of medicinal plants and fodder, to prohibit the cutting of fruit trees, and to protect seed-dispersing wildlife. The initial fear of villagers that the monitoring would lead to more restrictions in resource use has partly become a truth. Until now the management knowledge confines itself to either restriction, or use. There is still too limited knowledge on the management options in between both extremes: sustainable use. To prevent villagers losing interest in the monitoring in the long run, training in sustainable use would provide them with more benefits. As the monitoring team currently does not consist of a full representation of the village, it is crucial for the team to continue to enlarge participation of other villagers in the monitoring and analysis of findings, to enhance ownership of management actions in the whole village.

For other management suggestions, villagers feel external support is needed from the management office, such as for the cultivation of medicinal plants, the strengthening of awareness, habitat management, and to allow seasonal collection and selling of wild vegetables and fungi. In case the actions fall outside their mandate, the management staff reported to decision-makers at higher levels (prefecture or provincial forestry bureau). An example of this type of problem is the increased sugarcane plantations.

Results show that most management actions that need to be taken at the level of management office (and higher) are not yet implemented. Only cultivation of medicinal plants has been implemented with financial support from the management office. Also some awareness building activities have been done. Possibly this is because there is not enough knowledge about how to improve habitat management and how to sustainably use resources. Another reason could be that the management staff are yet not enough involved in PRM to see the monitoring as a management tool.

\section{Other benefits: social change through participatory monitoring}

Literature indicates that participatory monitoring could also be considered a social, cultural and political process of bringing people together in new ways, coming to understand different views and enhancing democratic decision-making on what types of measures to take (Guijt et al. 1998). It may enable experimental learning and negotiation, contributing to building trust and changing perceptions, behaviour and attitudes among stakeholders (Estrella and Gaventa 1998). It may also build social capital (Bliss et al. 2001; see also Becker et al. 2005 (this issue)). Success is not primarily determined by the products, but by the quality of the process (Agrawal and Gibson 1999; Schanz 2002). The PRM also seems to have started a social and political process, building social capital and leading to social change. 
These indications are based on narratives and can not be presented as results in this paper. In order to test the validity of indications of social change through participatory monitoring, social indicators could be included in the monitoring methodology. More specific components of social change through PRM are discussed below.

Building trust, improve relations between villagers and staff

All villagers expressed that they can better manage their resources after 1 year of PRM implementation, because they understand the dynamic changes of species. They were also enthusiastic about making a biological specimen. Staff from the protected areas also started to show interest in indigenous knowledge. For example, staff from the Ruili Forestry Bureau expressed their wish to invite indigenous experts to assist them construct their botanical garden, by providing seedlings and seeds that are difficult to find. Villagers shared their knowledge with management staff e.g. on medicinal plants and their use. Some of this knowledge was new for staff, e.g. to use Eupatorium ('airplane grass', in general regarded as a pest) against malaria and liver diseases. Villagers also said that through monitoring, relations among villagers generally improved, as it created more occasions for interaction during 'interviews' and village meetings. PRM therefore seems a valuable tool to improve the communication and understanding between villagers and government staff.

\section{Changing perceptions, behaviour and attitudes}

The technical results from the monitoring show that villagers and government staff realised that forests not only need to be managed for timber and fuel wood but also for NTFPs and wildlife. During meetings to discuss the reasons behind the monitoring findings, villagers were given an opportunity to appreciate more indirect, complex links between resource abundance and use. They subsequently suggested changing their behaviour, in particular by drafting rules for sustainable use, forbidding collection from the wild and encouraging domestication instead. Although the forestry bureau also reports on wildlife damage, this issue was included in the PRM to stimulate local reflections on causes of wildlife damage. The prevailing idea among villagers and staff was that wildlife and forests were better conserved, resulting in increased populations of wildlife and thus an increase in wildlife damage. Through PRM, wildlife damage is linked to wildlife abundance and the quality of the habitat. The majority of the villages in Tongbiguan and Xiaoheishan now had the understanding that the wildlife habitat may still be too degraded, causing the animals to go for more easily obtainable food such as corn and sugarcane in the villagers' fields. Villagers in Xiaoheishan also believed that populations of smaller wildlife (such as Sus scrofa) increased due to a decline in populations of predators (such as Panthera pardus).

Bring people together in new ways

The PRM created an opportunity for staff and villagers to regularly meet (in general a few times a year) and discuss their perceptions of forests and 
how they should be managed. Staff acknowledged that communicating with villagers was a new experience for them, and that it has consequences for their technical capacities. Their approach to villagers used to be top-down and rules and regulations were propagated with limited discussion. In the participatory monitoring there was a two-way discussion, during which staff got unexpected questions to which they had no answer. As a result, they expressed an interest in receiving more training in ecology and methods for sustainable resource use, to be able to provide villagers with appropriate answers. Some villagers expressed their wish for training in the use and cultivation of medicinal plants. 'Indigenous experts' from villages with similar conditions expressed their willingness to provide this training. This inter-villager training had not been suggested before.

Democratic and transparent decision-making

Participatory resource monitoring also contributed to a more democratic decision-making on forest management issues. When the monitoring started, villagers said that some of the current regulations drafted by the forestry and management bureau were not realistic and not based on the local situation. Through PRM the government staff and villagers were able to draft more location-specific rules and regulations, based on local perceptions and knowledge. Whether this has led to better management is still too early to say.

\section{Accuracy}

The monitoring results presented in this paper are villagers' perceptions of reality. 'Reality' is however socially constructed (Berger and Luckmann 1981). Different people perceive, understand and value reality (e.g. resource abundance) differently due to different worldviews, knowledge systems, values and beliefs. Because they construct problems differently, they will also suggest different management actions (Malhotra 2001; Wilshusen et al. 2002; Wong et al. 2002). For this reason a pluriformity between professional and community-based forest management systems exists (Wiersum 1999). This pluriformity in management suggestions will also be present within the village, as a community is heterogeneous (Agrawal and Gibson 1999; Leach 2002). As stakeholders may interpret and construct problems and trends differently according to their cultural underpinnings, we argue that community-based monitoring is not necessarily less accurate than scientific monitoring (see also Danielsen et al. 2005 (this issue)). To optimise accuracy would in our opinion mean to compare the perceptions of different stakeholders in monitoring. That would mean to better link participatory monitoring with scientific monitoring and patrolling. Conceptual frameworks and methods linking local and scientific assessment and values are still scarce (Lawrence 2002). 
According to Ambrose-Oji et al. (2002) one of the most important challenges faced by natural resource managers today is to understand people's perceptions towards forests, value judgements towards problems and motivations for management actions. If we understand why and how people perceive, analyse and decide the way they do in resource management, we can better facilitate a negotiation between different stakeholders about which management action to take. Only then we can effectively facilitate an exchange of scientific, technical and local/indigenous knowledge systems and an integrated decision-making process.

\section{Sustainability}

The participatory monitoring was financially supported in the first year, with a major decrease in support in the second year. It remains unknown whether this limited financial support is sufficient to motivate villagers and staff to continue the monitoring. Sustainability on the long run is, however, not achieved through financial support. Sustainability implies a continuous learning and construction of reality. The constructed reality and multistakeholder learning is sustained through discussions and conversation with others (Berger and Luckmann 1981). Through discussion, stakeholders come to interpret themselves and their relation to each other by elaborating a common understanding of the world (Sabel 1994). Participatory monitoring aiming to produce knowledge to inform decision-makers and catalysing social change is only sustainable if it leads to the creation or adaptation of institutional arrangements, through which various stakeholders can continuously exchange and interact ('discursive institution'). Building these institutions will increase the likelihood that what is learnt will also inform future resource management decisions. The example described in this paper has not survived for long enough to know whether this has happened. Part of the building of discursive institutions is the integration of community work in the job description of management staff. In our case, to date, this has not yet been the case, which is the reason why it has been difficult to motivate management staff to be closely involved in the participatory monitoring.

A second factor determining sustainability is legislation on the rights of villagers to access and use resources in the protected areas. To a certain extent this is the case in the nature reserves in Yunnan (see Introduction).

\section{Scaling up}

We believe the participatory monitoring approach can be applied in other parts of China. In fact, PRM has recently been started in two other nature reserves in 
Yunnan, without external financial support. We also think that such a direct involvement of villagers in the whole process of monitoring makes sense in areas where people's livelihoods are (partly) based on forests and in areas where urgent management action is needed for resources under threat.

In efforts to scale up to national or even global levels, it may be more important for national monitoring systems to accept and integrate (qualitative) information relevant to local needs, values, realities and constructions instead of vice versa. Most of the current monitoring targets in PRM are not of international importance, though some are of national importance. Instead of putting all efforts in a discussion on whether and how participatory monitoring can become valuable for national or global monitoring systems, we should pay more attention to how national policy-makers could become interested in what is done locally.

\section{Acknowledgements}

This paper is an expanded version of a presentation we were invited to make at a symposium on locally-based monitoring in Denmark in April 2004 (www.monitoringmatters.org). The symposium was organised by the Nordic Agency for Development and Ecology (NORDECO, Denmark), and the Zoology Department of Cambridge University (UK). The field research which formed the basis for this paper was implemented under the Forest Conservation and Community Development Project (FCCDP), funded by the Dutch and Chinese governments. We thank all villagers and nature reserve management and forestry staff participating in PRM for sharing their knowledge, enthusiasm and inspiration. We thank F. Wiersum, H. Schanz and N. Burgess for helpful comments on earlier drafts. 


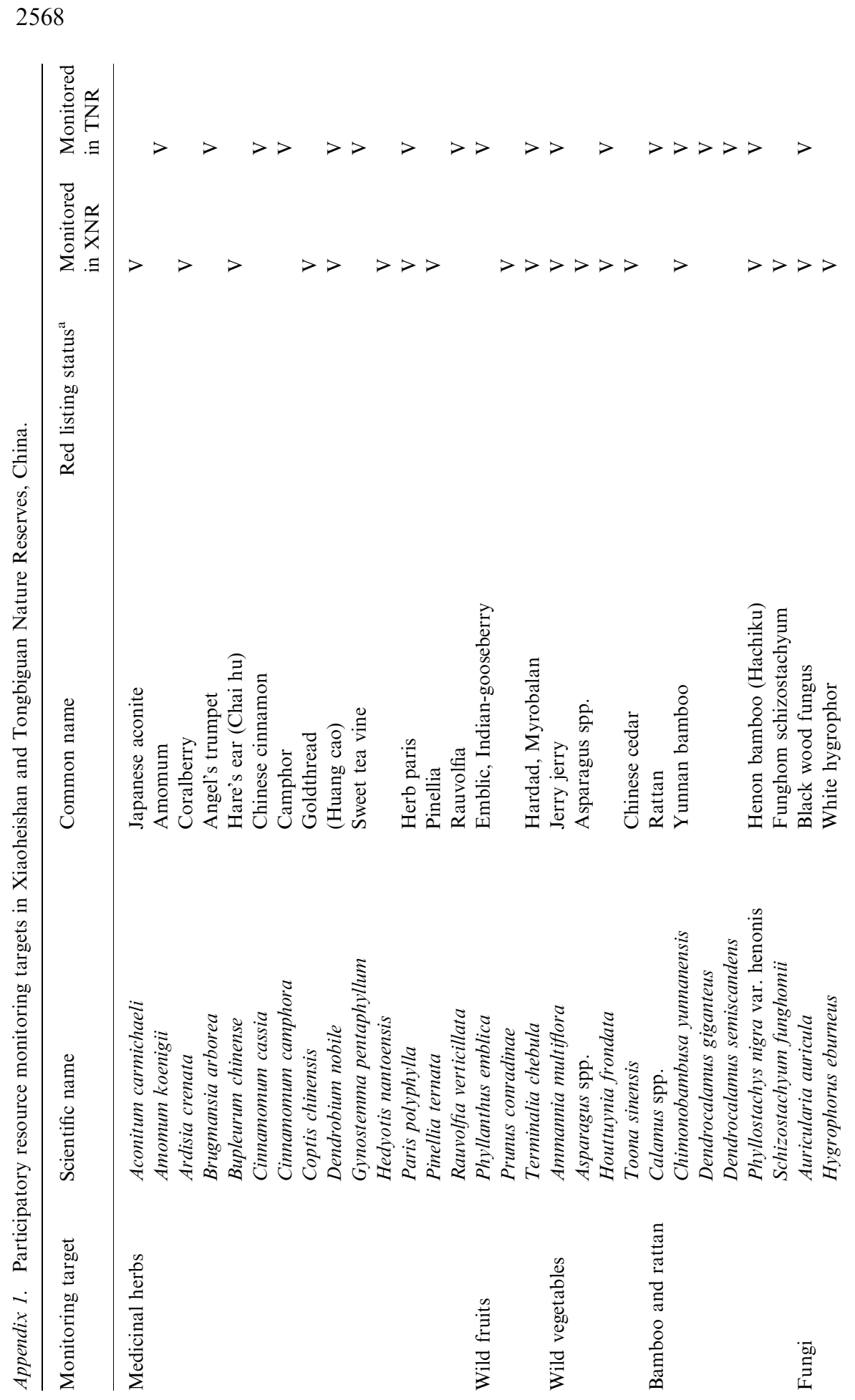




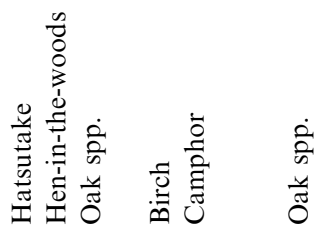

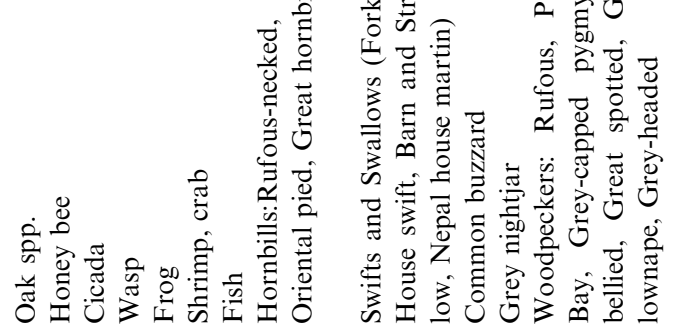

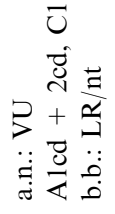

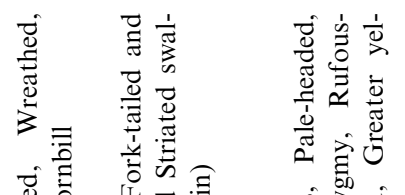

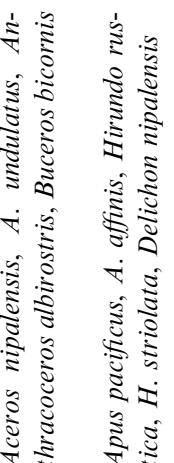

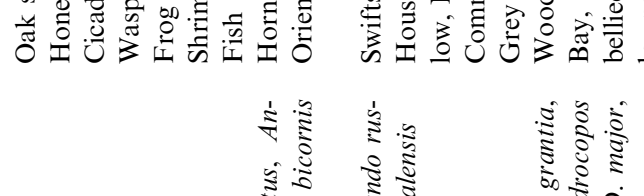

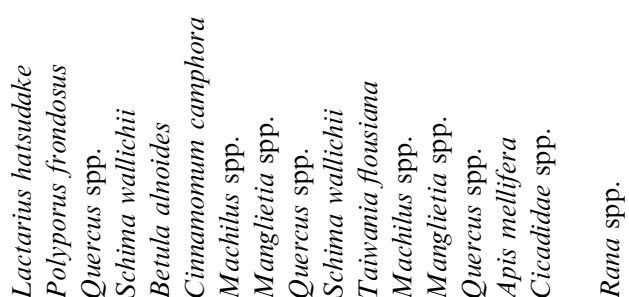

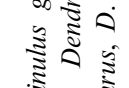
ปัँ

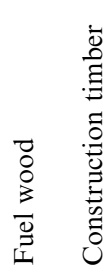

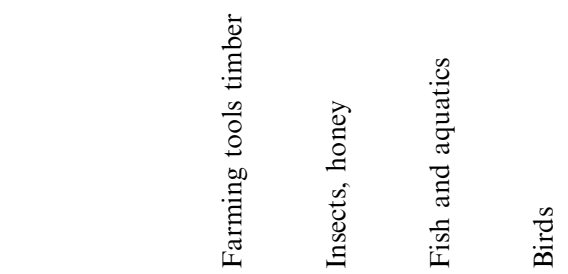

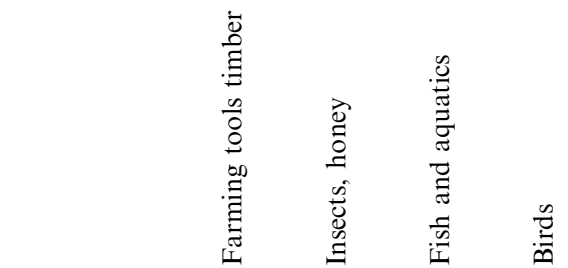

औरำ

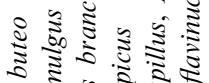

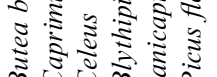




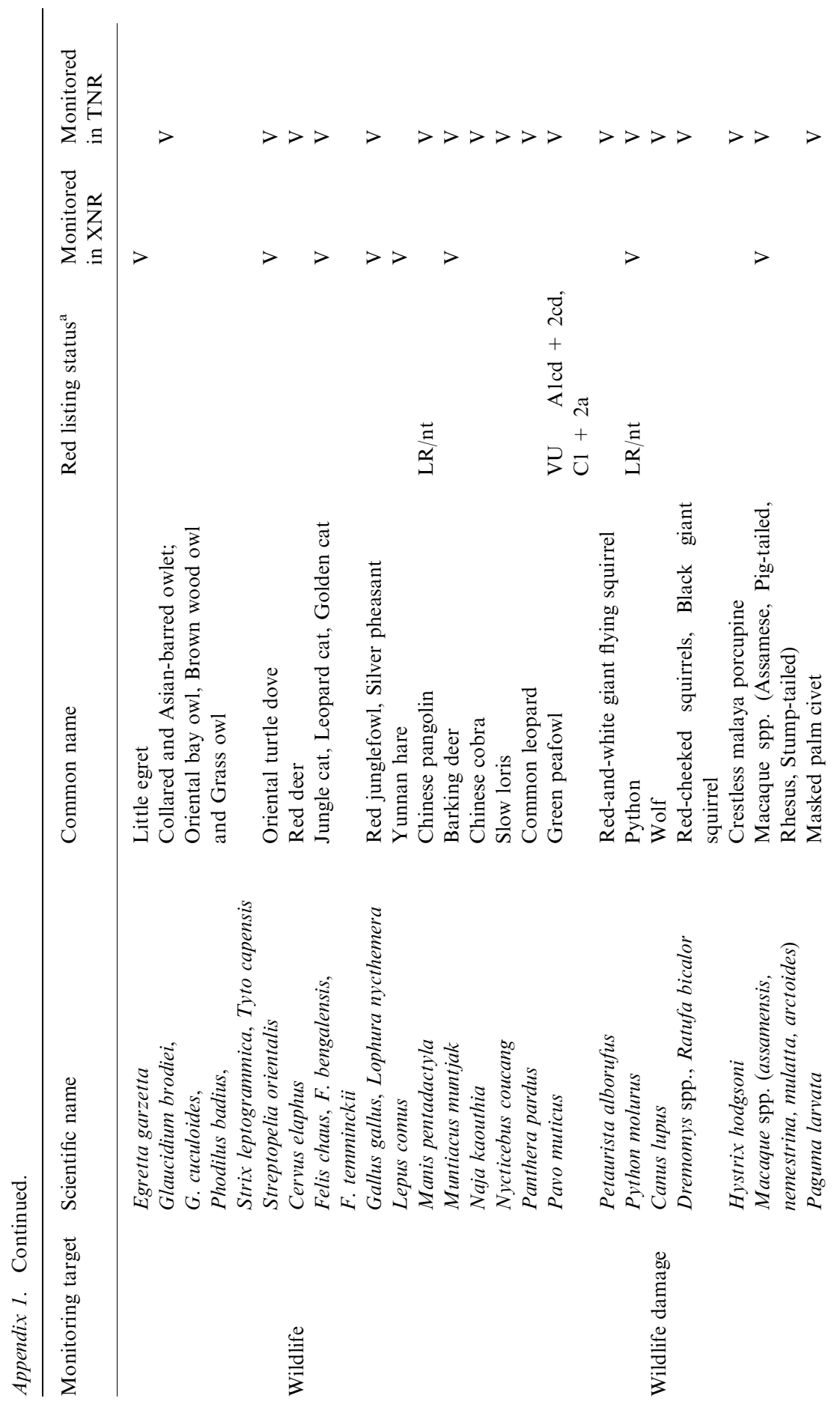




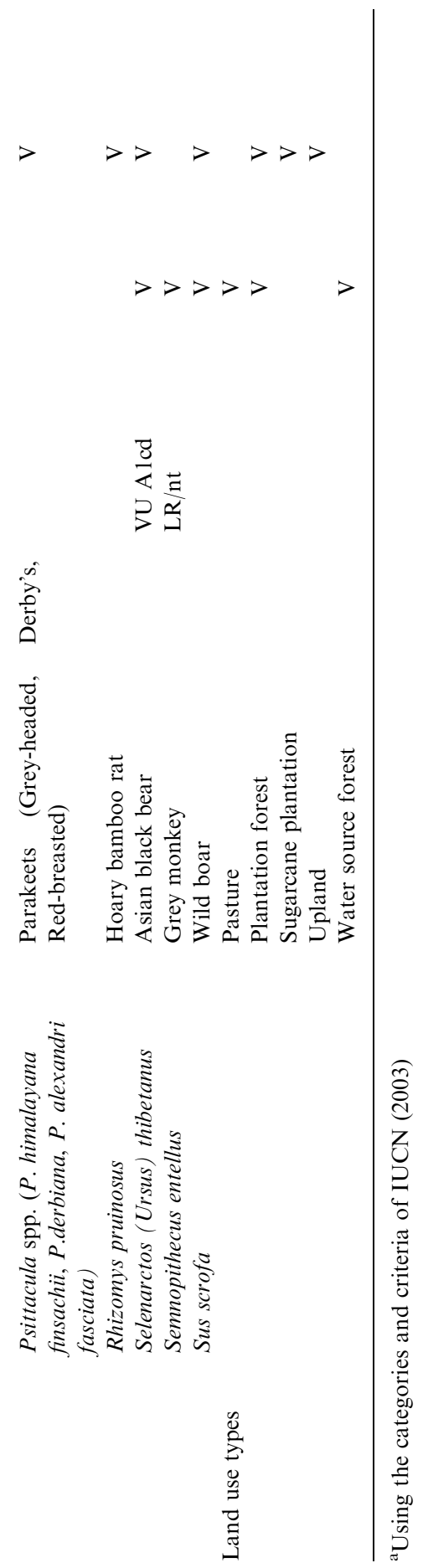




\section{References}

Agrawal A. and Gibson C.C. 1999. Enchantment and disenchantment: the role of community in natural resource conservation. World Develop. 27: 629-649.

Ambrose-Oji B., Lawrence A., Wong J., Lysinge R., Fraser P., Hall J., O'Connor H. and Healey J. 2002. Obtaining local values for biodiversity: protocols used by the ERP Mount Cameroon Project. Summarised case study. In: ETFRN (ed.), Internet Conference on Participatory Assessment, Monitoring and Evaluation of Biodiversity (PAMEB). 7-25 January 2002. ETFRN, Environmental Change Institute DFID and Tropenbos International.

Becker C.D., Agreda, A., Astudillo E., Constantino M. and Torres P. 2005. Community-based surveys of fog capture and biodiversity monitoring at Loma Alta, Ecuador enhance social capital and institutional cooperation. Biodiversity and Conservation 14: 2695-2707.

Berger P.L. and Luckmann T. 1981. The social construction of reality: a treatise in the sociology of knowledge. Penguin, Harmondsworth.

Bliss J., Aplet G., Hartzell C., Harwood P., Jahnige P., Kittredge D., Lewandowski S. and Soscia M.L. 2001. Community-based ecosystem monitoring. J. Sustain. Forest. 12: 143-167.

Danielsen F., Burgess N. and Balmford A. 2005. Monitoring matters: examining the potential of locally-based approaches. Biodiversity and Conservation 14: 2507-2542.

Dupar M. and Badenoch N. 2002. Environment, Livelihoods, and Local Institutions. Decentralisation in Mainland Southeast Asia. World Resources Institute, Washington DC, USA.

Estrella M. and Gaventa J. 1998. Who counts reality? Participatory monitoring and evaluation: a literature review. Institute of Development Studies, Brighton, UK.

Fisher R.J. 1995. Collaborative management of forests for conservation and development. Issues in forest conservation. IUCN and WWF, Gland, Switzerland.

Guijt I., Arevalo M. and Saladores K. 1998. Tracking change together. In: Arevalo M. et al. (eds), PLA Notes 31: Participatory Monitoring and Evaluation. IIED, London, UK, pp. 28-36.

IUCN 2003. 2003 IUCN Red List of Threatened Species. www.redlist.org.

Kellert S.R., Mehta J.N., Ebbin S.A. and Lichtenfeld L.L. 2000. Community natural resource management: promises, rhetoric, and reality. Soc. Nat. Resour. 13: 705-715.

Lawrence A. 2002. The Art of Science: Background Paper for the ETFRN PAMEB Conference. In: ETFRN (ed.), Internet Conference on Participatory Assessment, Monitoring and Evaluation of Biodiversity (PAMEB). 7-25 January 2002. ETFRN, Environmental Change Institute DFID and Tropenbos International.

Lawrence A. and Elphick M. 2002. Summary report. In: Lawrence A. and Elphick M. (eds), Policy Implications of Participatory Biodiversity Assessment. ETFRN International Seminar for Policy-Makers and Implementers, London, UK. ETFRN Environmental Change Institute, DFID and Tropenbos International.

Lawrence A. and van Rijsoort J. 2003. How should a participatory biodiversity assessment be conducted? In: UNEP World Conservation and Monitoring Centre (ed.), Biodiversity Assessment and Monitoring. Guidance for Practitioners. UNEP-WCMC, Cambridge, UK.

Leach M. 2002. Plural perspectives and institutional dynamics: challenges for community forestry. In: Oglethorpe J.A.E. (ed.), Adaptive Management: From Theory to Practice. IUCN, Gland, Switzerland and Cambridge, UK, pp. 66-82.

Li Z.B., Zhao X.D., Yang S.Y., Shi X.C., Yang X.H., Ning B., Cheng B.R., Zhang S.Q., Zhang Y.B., Liu H.Z., Xia L. and Li A.P. 1999. Preliminary Integrated Management Plan of the provincial level Xiaoheishan Nature Reserve. Unpublished project report. Xiaoheishan Nature Reserve Management Office, Baoshan, Yunnan, P.R. China.

Malhotra Y. 2001. Expert systems for knowledge management: crossing the chasm between information processing and sense making. Expert Syst. Appl. 20: 7-16.

van Rijsoort J. and Zhang J. 2002. Development of participatory resources monitoring in two nature reserves in Yunnan, P.R. China. A case study. In: ETFRN (ed.), Internet Conference on Participatory Assessment, Monitoring and Evaluation of Biodiversity (PAMEB). 7-25 January 2002. ETFRN, Environmental Change Institute, DFID and Tropenbos International. 
van Rijsoort J. and Zhang J. In press. The development of a strategy for Participatory Resources Monitoring in Yunnan, P.R. China and its value for forest conservation and local needs. In: Lawrence A. (ed.), Taking Stock of Nature. Cambridge University Press, Cambridge, UK.

Sabel C.F. 1994. Learning by monitoring: the institutions of economic development. In: Smelser N.J. and Swedberg R. (eds), The Handbook of Economic Sociology. Princeton Press and Russel Sage Foundation, Princeton, NJ and New York, USA.

Schanz H. 2002. National forest programmes as discursive institutions. Forest Policy and Economics 4: 269-279.

Sheil D. 2001. Conservation and biodiversity monitoring in the Tropics: realities, priorities, and distractions. Conserv. Biol. 15: 1179-1182.

Wiersum K.F. 1999. Normative pluriformity in forest management: professional and community perspectives. In: FAO et al. (eds), Pluralism and Sustainable Forestry and Rural Development. FAO, Rome, Italy. 9-12 December 1997, pp. 365-380.

Wilshusen P.R., Brechin S.R., Fortwangler C.L. and West P.C. 2002. Reinventing a square wheel: critique of a resurgent 'protection paradigm' in international biodiversity conservation. Soc. Nat. Resour. 15: 17-40.

Wong J., Healey J. and Phyllips O. 2002. Incorporating values into biodiversity assessment and monitoring - An introduction to some current issues. In: ETFRN (ed.), Internet Conference on Participatory Assessment, Monitoring and Evaluation of Biodiversity (PAMEB). ETFRN, Environmental Change Institute, DFID and Tropenbos International.

Xu J., Zuo T. and Yang Y. 2001. The Impact of Decentralisation and Local Participation on Upland Watersheds Management in Yunnan, China. A collaborative Project between Resources Policy Support Initiative (REPSI) and Centre for Biodiversity and Indigenous Knowledge (CBIK). Project document. Centre for Biodiversity and Indigenous Knowledge (CBIK), Kunming, P.R. China.

Zhuo P.Y., Qu L.S., Chang Z.J. and Peng H.F. 2000. Preliminary Integrated Management Plan of the Provincial level Tongbiguan Nature Reserve. Unpublished project document.Tongbiguan Nature Reserve Management Office, Mangshi, Yunnan, P.R. China. 